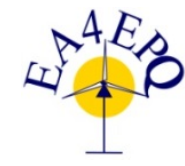

International Conference on Renewable Energies and Power Quality (ICREPQ'17)

Malaga (Spain), $4^{\text {th }}$ to $6^{\text {th }}$ April, 2017

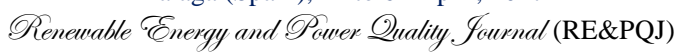

ISSN 2172-038 X, No.15 April 2017

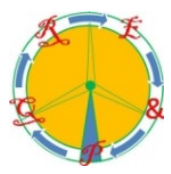

\title{
Analysis of Radio Signal coverage of a feeder using Radio Mobile Software
}

\author{
Arnulfo Barroso de Vasconcellos ${ }^{1}$, Saulo Roberto Sodré dos Reis ${ }^{1}$, Gabriela Pessoa Campos ${ }^{1}$, Priscila \\ Costa Nascimento ${ }^{1}$, Fabricio Parra Santilio ${ }^{1}$ e Teresa Irene de Ribeiro de Carvalho Malheiro ${ }^{2}$ \\ ${ }^{1}$ Department of Electrical Engineering \\ Federal University of Mato Grosso - UFMT. Av. Fernando Corrêa da Costa, nº 2367 - District Boa Esperança. Cuiabá - MT. \\ arnulfo@ufmt.br, saulo@ufmt.br, gabriela_pessoacampos@hotmail.com, costapri96@gmail.com, fabricio.qee@gmail.com \\ ${ }^{2}$ Federal Institute of Mato Grosso - IFMT. Avenue Sen. Filinto Müller, 953. Cuiabá - MT. \\ malheiro.teresa@gmail.com
}

\begin{abstract}
Summary - The study of propagation of signals by means of theoretical models in power distribution lines using computational tools has become important to forecast the propagation environment, as well as the identification of communication failures that decrease the signal coverage or block transmission completely, implying in the increase of service quality indicators penalties, and the average time of service, TMAE.

Thus, an analysis was made of the propagation environment in the region of a feeder located in the state of Mato Grosso, from the choice of critical points and distant from the Substation. Initially, the objective was to identify possible shadow areas, considering the terrain profile in the feeder region and obstacles present in the path between transmitter and receiver. Computer simulations were performed with the parameters of radio and irradiating system using the Radio Mobile software.

The objective of the study was to analyze the radio signal coverage of a feeder, verifying obstruction points and the impact of these in the communication and the attendance of the teams, considering aspects of feeder topology, road access and terrain conditions.
\end{abstract}

Keywords - Radio Communication, Signal Propagation, Quality of Service Indexes, Average Time of Service.

\section{INTRODUCTION}

The state of Mato Grosso (MT) has an area of approximately 903,386.1 $\mathrm{km}^{2}$ with plateaus in the center, plain with marshes to the west and depressions and plateaus to the north. The energy market in the state of Mato Grosso presented in 2015 an average demand for active power of around $1.9 \mathrm{GW}$ and an energy consumption of around 8,537 GWh, with increasing characteristics of expansion with the entry of new industries in the agribusiness sector.

However, this growth is not accompanied by the transportation infrastructure despite being made basically of road transport. Of the more than $84,000 \mathrm{~km}$ of highways in the state, only about $5 \%$ are paved. The lack of conservation of the roads and at the same time, the unfavorable climatic conditions at some periods of the year hinders the movements of the power distributor's service teams. In addition, the terrain arrangement in some regions and the large distances added to the lack of coverage for communication systems such as mobile phones and radio telephony end up making communication of power distributors communication centers with the field teams difficult, causing delays in maintenance, communication failures and insecurity for the field teams.

One of the main activities of electric power distribution companies is servicing technical and commercial requests. In general, task distribution among the various teams that perform the requests is done considering the request profile and the service region of the teams, which can lead to a non homogeneous division of tasks between them, overloading some teams, dropping quality, leaving some teams idle, reducing operational efficiency and increasing company spending. The deadlines for meeting the various types of commercial service requests are determined by the National Electric Energy Agency (ANEEL). In order for distribution utilities to reach such targets, they need to scale and monitor their field teams so that there is no surplus or shortage of teams per region, aiming for a satisfactory service to users at a reduced cost. In addition to the sizing of the teams, it is necessary to designate them at the service locations so that the time of travel of the available and properly equipped teams to the aforementioned locations is as small as possible.

This article analyzes the radio signal propagation environment in the region of a feeder, using Radio Mobile software. This is free and available for radio amateurs and for educational purposes, adopting the Irregular Terrain propagation model (ITM), also known as Longley-Rice model. This tool allows simulations for point-to-point link situations or point-to-area situations to check the coverage of the radio signal. Terrain elevation data can be obtained for free from different image bases, such as NASA (STRM), Open Street Map, TerraServer, Google Earth, among others. 


\section{Service Quality Indicators}

According to the National Electric Energy Agency (ANEEL), electricity distribution companies are evaluated by service continuity indicators, both collective and individual. The collective indicators are called DEC and FEC, and the individual DIC / FIC, and are calculated monthly by the distributors. The DEC indicator represents the equivalent duration of interruption per consumer unit, while the FEC expresses the equivalent frequency of interruption per consumer unit [1]

The determination of the DEC indicators is carried out according to ANEEL Resolution No. 024, dated January 27, 2000, according to the following formula:

$$
D E C=\frac{\sum_{i=1}^{n} C a(i) \times t(i)}{C s}
$$

Being:

DEC $=$ Equivalent Duration of Interruption per Consumer, expressed in hours and hundredths of an hour;

$\mathrm{n}=$ Number of interruptions in the observation period;

$\mathrm{i}=$ Counter of the number of interruptions, ranging from 1 to $\mathrm{n}$;

$\mathrm{Ca}(\mathrm{i})=$ Number of consumers, of the set considered, reached at interruption (i);

$\mathrm{t}(\mathrm{i})=$ Interruption time (i), in hours;

Cs $=$ Total number of consumers in the set considered.

According to the same resolution mentioned above, the FEC is calculated according to the following formula:

$$
F E C=\frac{\sum_{i=1}^{n} C a(i)}{C s}
$$

Being:

FEC = Equivalent Frequency of Interruption per Consumer, dimensionless number expressed to two decimal places; $\mathrm{n}=$ Number of interruptions in the observation period; $\mathrm{i}=$ Counter of the number of interruptions, ranging from 1 to $\mathrm{n}$;

Ca (i) = Number of consumers, of the set considered, reached at interruption (i);

Cs = Total number of consumers of the set considered;

Emergency attendance is supervised, evaluated and controlled through indicators that express the values linked to consumer units groups. These indicators are the average time of preparation of the maintenance team, the mean time of displacement and the average time of execution. These indicators are calculated as follows: a) Average Time of Preparation of Emergency Response Teams (TMP)

$$
T M P=\frac{\sum_{i=1}^{n} T P(i)}{n}
$$

At where:

$\mathrm{TMP}=$ mean time of preparation of the emergency response team, expressed in minutes;

TP (i) = time of preparation of the emergency response team for each emergency occurrence, expressed in minutes;

$\mathrm{n}=$ number of emergency occurrences verified in the set of consumer units, in the calculation period considered;

Indicates the efficiency of the media, team dimensioning and information flow of the operation center.

b) Mean Time of Displacement (TMD)

$$
T M D=\frac{\sum_{i=1}^{n} T D(i)}{n}
$$

At where:

$\mathrm{TMD}=$ mean travel time of the emergency response team, expressed in minutes;

TD (i) = travel time of the emergency response team for each emergency occurrence, expressed in minutes; $\mathrm{n}=$ number of emergency occurrences verified in the set of consumer units, in the calculation period considered; Indicates the influence of geographic location of maintenance teams.

c) Mean Execution Time (TME)

$$
T M E=\frac{\sum_{i=1}^{n} T E(i)}{n}
$$

At where:

TME = average time of execution of the service until its reestablishment by the emergency response team, expressed in minutes;

$\mathrm{TE}$ (i) = time of execution of the service until its reestablishment by the emergency response team for each emergency occurrence, expressed in minutes;

$\mathrm{n}=$ number of emergency occurrences verified in the set of consumer units, in the calculation period considered; Indicates the efficiency of re-establishing the distribution system by the maintenance and operation teams.

The Average Time of Emergency Care is obtained by summing the three indicators above. This is,

$$
T M A E=T M P+T M D+T M E
$$


At where:

TMAE $=$ mean time of attendance to emergency occurrences, representing the average time for emergency care, expressed in minutes;

Figure 01 shows the service quality indexes, DEC and FEC, from Mato Grosso in the period from 2010 to 2014. Through this histogram, it is possible to notice that in the years 2012 to 2014, DEC exceeded the limits recommended by ANEEL, and FEC exceeded the limits in 2012 and 2013 [2].

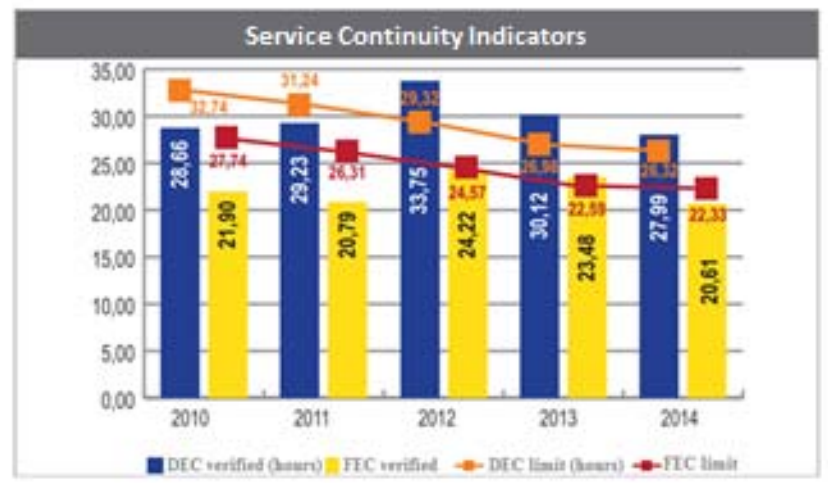

Fig. 01. Service quality indexes, DEC and FEC of Mato Grosso.

DEC represents the amount of time consumers were left without electricity. The causes of these disconnections are lightnings, birds or animals, equipment failures, among others. When the distributor has DEC and FEC limits higher than those recommended by ANEEL, it suffers penalties.

Another service quality indicator is TMAE, which indicates the average time of emergency care. This indicator is composed by three parts, one of which is the team's travel time, which comprises the time the maintenance team takes to find the defect and move to that point. Often, this process is hampered by the communication difficulties of the plant with the maintenance teams.

Therefore, it is interesting to study how the distribution system of the distributor is, and for this it is necessary to analyze the radio signal coverage in the State.

\section{Analysis of Radio Signal Propagation Conditions in the Studied Feeder Region}

The study of signals propagation using theoretical models and computational tools has become important to predict the propagation environment and to identify obstructions that reduce the signal coverage or completely block its transmission.

The proposed feeder study uses the Irregular Field Propagation Model (ITM), also known as Longley-Rice model [3]. This model calculates the mean signal loss based on the terrain profile and troposphere refractive conditions
[4]. The model may be used to predict signal loss in a pointto-point link condition or in a point-to-area condition.

In this study, the computational simulations using the Longley-Rice model are aimed at verifying the conditions of signal coverage and possible obstruction points that impact the sending of work orders to the maintenance teams in real time.

The feeder studied serves part of its consumers in a rural area far from the substation and difficult to access. From the topology of the feeder, shown in figure 02, and considering the access conditions for the maintenance teams, critical points were chosen at the ends of the feeder for the study.

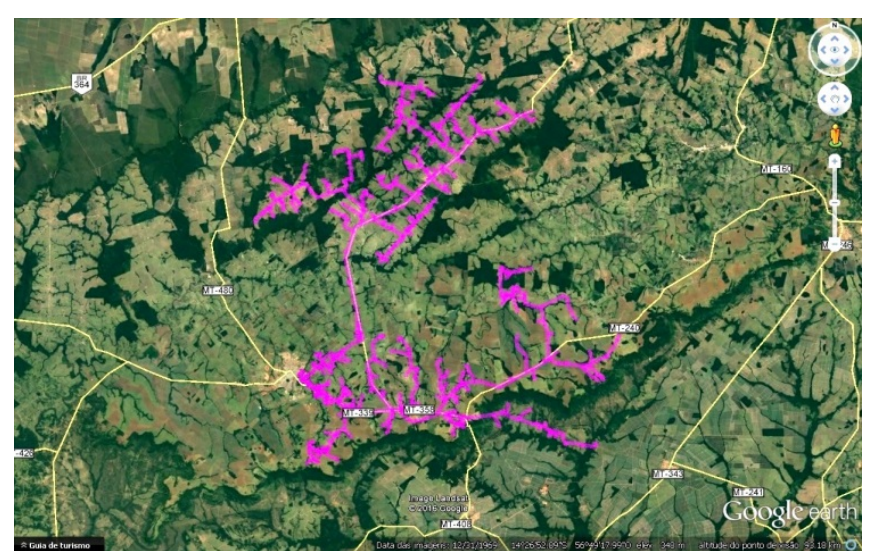

Fig. 02: Topology of the Feeder chosen for the study.

From the critical points, and from information about the terrain profile and information about the communication system between the operations center and the maintenance teams, computational simulations were performed to identify possible shadow regions and obstacles present in the path between transmitter and Receiver.

\section{Computational Simulations}

The definition of reception points for analysis of the radio signal coverage was based on the feeder topology, as shown in Figure 02, and the field inspection of some of the feeder sections. Initially, points at the feeder end were chosen which represent theoretically difficult access points for the field crews and at the same time obstruction points of the RF signal. Based on this information, 9 points were defined from the Substation and 9 radials were drawn for analysis. Figure 03 illustrates one of these chosen radials. For each radial terrain profiles were obtained using the available databases in software environment Mobile Radio ${ }^{\circledR}[5]$. 


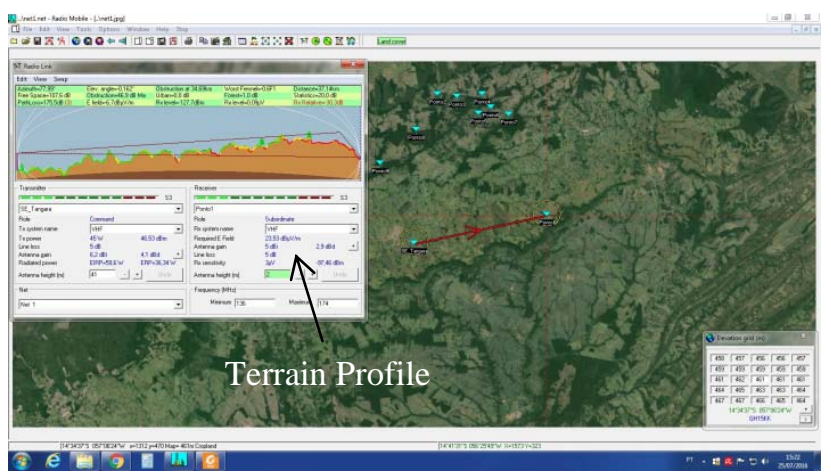

Fig. 03: Illustration of one of the 9 radii chosen for the computational simulations and the terrain profile between the substation and chosen point.

\section{Results}

Computational simulations were performed for each of the radials considering a point-to-point connection situation between the substation and the points located at the ends of the feeder. The information of the communication system of the substation and the reception system available in the vehicles of the maintenance teams was inserted in the computational model.

In all, 58 points of obstruction were identified along the feeder, however, most of the identified obstruction sections are located in distant regions of the line or even at points where the teams do not move to service, so they are not considered of interest for the study. Thus, 9 points will be presented that have a significant impact on the system.

Table 1 presents the results obtained for each of the chosen radial. In each radial all the sections of obstruction of the signal were identified with their coordinates and distance. The radials that connect the substation to points 4 , 5 and 6 have the largest number of stretches with obstruction of the signal. Radials 2, 4 and 7 present the longest stretches of signal jamming from the transmitter located at the substation. The obstruction sections were defined considering that the reception threshold of radios in the Car the staff is approximately $0.22 \mathrm{mV}(-120 \mathrm{dBm})$ and the received levels are below this threshold value.

Table 1 - Simulated Reception Points in Radio Mobile and Obstructions found.

\begin{tabular}{|c|c|c|c|}
\hline \multirow[t]{2}{*}{ Radial } & \multirow{2}{*}{$\begin{array}{c}\text { No. } \\
\text { Stretches } \\
\text { blocked }\end{array}$} & \multicolumn{2}{|c|}{ Greater obstruction } \\
\hline & & Localization & $\begin{array}{c}\text { Distance } \\
\text { (km) }\end{array}$ \\
\hline Point 1 & 5 & $\begin{array}{c}\text { Start: } \\
14^{\circ} 35^{\prime} 34.0^{\prime \prime} \mathrm{S} \\
57^{\circ} 10^{\prime} 57.5^{\prime \prime} \mathrm{W} \\
\text { End: } \\
14^{\circ} 34^{\prime} 37.5^{\prime \prime} \mathrm{S} \\
57^{\circ} 06^{\prime} 24.2^{\prime \prime} \mathrm{W}\end{array}$ & 8,34 \\
\hline Point 2 & 6 & $\begin{array}{c}\text { Start: } \\
14^{\circ} 25^{\prime} 14.6^{\prime \prime} \mathrm{S} \\
57^{\circ} 24^{\prime} 27.3^{\prime \prime} \mathrm{W} \\
\text { End: }\end{array}$ & 15,85 \\
\hline
\end{tabular}

\begin{tabular}{|c|c|c|c|}
\hline & & $\begin{array}{l}14^{\circ} 16^{\prime} 47.3^{\prime \prime} \mathrm{S} \\
57^{\circ} 23^{\prime} 04.4^{\prime \prime} \mathrm{W}\end{array}$ & \\
\hline Point 3 & 6 & $\begin{array}{c}\text { Start: } \\
\text { 14²24'29.5”S } \\
57^{\circ} 22 \text { '18.5”W } \\
\text { End: } \\
\text { 14'18'59.4”S } \\
57^{\circ} 20^{\prime} 42.1 \text { ”W }\end{array}$ & 10,29 \\
\hline $\begin{array}{l}\text { Point } 4 \\
\end{array}$ & 7 & $\begin{array}{c}\text { Start: } \\
\text { 14²0'31.6”S } \\
\text { 57¹9'55.4”W } \\
\text { End: } \\
\text { 14'16'48.1.5”S } \\
\text { 57¹6'16.5”W }\end{array}$ & 15,74 \\
\hline Point 5 & 9 & $\begin{array}{c}\text { Start: } \\
\text { 14²5'44.1”S } \\
57^{\circ} 19^{\prime} 56.7^{\prime \prime} \mathrm{W} \\
\text { End: } \\
\text { 14²4'15.1”S } \\
\text { 57¹9'10.9”W }\end{array}$ & 3,07 \\
\hline Point 6 & 9 & 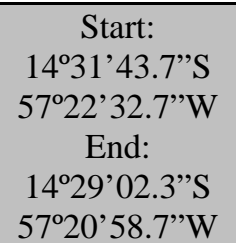 & 5,72 \\
\hline Point 7 & 6 & 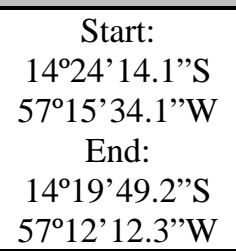 & 10,16 \\
\hline $\begin{array}{l}\text { Point } 8 \\
\end{array}$ & 7 & 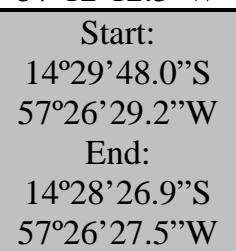 & 3,13 \\
\hline Point 9 & 3 & $\begin{array}{c}\text { Start: } \\
\text { 14²9'21.7”S } \\
\text { 57³0'52.1”W } \\
\text { End: } \\
\text { 14²7'01.0”S } \\
\text { 57³1'54.6”W }\end{array}$ & 4,73 \\
\hline
\end{tabular}

Thus, through the results obtained, it is perceived that the feeder presents communication failures in several stretches, due to the terrain profile and the communication system used. This fact has a direct impact on the TMAE, since one of the parts that compose it is the preparation time of the emergency response teams, which indicates the efficiency of the communication system. In this way, this feeder will negatively influence the DEC of the feeder set of the substation to which it belongs.

\section{Conclusion}

The growing improvement and optimization of processes supported by computer systems has led companies in the electricity distribution sector to increasingly seek a better 
harmonization of the following aspects: quality service to customer demands, compliance with regulatory requirements and need for adequacy Operating costs. This paper presents an analysis of the propagation of the communication signal of a feeder belonging to a substation located in the state of Mato Grosso.

In Brazil, distribution networks are mostly built in aerial structures (poles) because of their lower cost compared to underground networks. However, the aerial installation leaves the network more susceptible to the action of several agents, causing failures in its operation. These faults are usually designated by the term "faults", derived from the English term fault (i.e, defect). The most common causes of faults in the distribution network are road blocking by vehicles, lightning strikes, and tree branch drops and objects in the network.

The occurrence of a fault may cause interruption of the electricity supply, which requires an emergency intervention by the Distributor. The period of time elapsed from the occurrence of the fault to the reestablishment of the power supply is a critical factor for the concessionaire, which affects the company image, service billing and indicators monitored by ANEEL (National Electric Energy Agency). This period, which is called the TMAE, is composed of three parts: preparation time (between knowledge of the existence of an occurrence and the moment of authorization for the displacement of the team), time of displacement (Between the moment of authorization for the movement of the team to the moment of arrival at the site) and execution time (between the time of arrival at the place of occurrence and the restoration of the power supply).

This paper analyzed the radio signal coverage of a feeder using Radio Mobile software. By means of this analysis, it was verified that this feeder presents many points of obstructions of the signal, due to the terrain profile and the characteristics of the communication system. It is noticed that such behavior of the system directly impacts on the indicators of service quality of the set, implying in increase of the penalties suffered by the distributor. Therefore, it is recommended that studies should be performed to improve the coverage of the communication signal, reducing the TMAE as well as the DEC of the distributor, thus improving the quality of the service.

\section{BIBLIOGRAPHIC REFERENCES}

[1] ANEEL. Electricity Distribution procedures in the National Electric System (Prodist), module 8.

[2] Data and applications registered at the Mato Grosso Distribuidora. 2015. Available at page www2.aneel.gov.br/arquivos/PDF/EMT_OSN2015.pdf

[3] A. G. LONGLEY, P.L. RICE,a.p. BARSIS, Prediction of tropospheric radio transmission loss over irregular terrain a computer method, ERL65-ITS67. Washington: NTIA, 1968.
[4] RAPPAPORT, T. S., Wireless Communications - Principles and Practices, 2nd Edition, Prentice-Hall, 2009.

[5] Software Radio mobile, Available at Official Radio Mobile Page. http://www.cplus.org/rmw/english1. 